\title{
Synthesis and SAR Studies of Potent Antioxidant and Anti-Inflammatory Activities of Imidazole Derived Schiff Base Analogues \\ Shantharam CS ${ }^{1}$, Swaroopa $\mathbf{M}^{2}$, Darshini $\mathbf{N}^{3}$, Mallesha $\mathbf{N}^{3 *}$ and Rakesh KP $^{3 *}$
}

${ }^{1}$ Department of Chemistry, Pooja Bhagavath Memorial Mahajana Education Centre, Mysore-570016, Karnataka, India

${ }^{2}$ Department of Pharmaceutical Chemistry, Bharathi College of Pharmacy, Mandya-571422, Karnataka, India

${ }^{3}$ Sri Ram Chem, R \& D Centre, Plot No 31, JCK Industrial Park, Belagola Industrial Estate, Mysore-570016, Karnataka, India

\begin{abstract}
A novel sequence of imidazole derived Schiff base analogues 4-23 were synthesized and characterized by spectroscopic and analytical techniques. The in vitro antioxidant activities of these compounds were evaluated by using DPPH, ABTS and DMPD assay. The results exposed that the $\mathrm{IC}_{50}$ of compounds $9,10,11,15,16,22$ and 23 were lower than that of standards in all the three tested antioxidant assays indicating good activities of these compounds. In vitro anti-inflammatory activities of the synthesized compounds were tested and the outcomes of results were confirmed that the compounds $5,6,7,8,12,13,14$ and 21 exhibited excellent anti-inflammatory activity. Preliminary structure-activity relationship revealed that the compounds $9,10,11,15,16,22$ and 23 with electron donating moiety $\left(\mathrm{OH}, \mathrm{OCH}_{3}\right)$ were found to be excellent antioxidants and compounds $5,6,7,8,12,13,14$ and 21 with electron withdrawing moiety $(\mathrm{Cl}, \mathrm{F}$, $\mathrm{NO}_{2}$ and $\mathrm{Br}$ ) were found to be excellent anti-inflammatory agents.
\end{abstract}

Keywords: Imidazole; Anti-oxidants; Anti-inflammatory activity; Electronic properties

\section{Introduction}

Medicinal chemistry is an interdependenty established science that encompasses the innovation, progress, recognition and revelation of the mode of action of biologically dynamic compounds at the molecular level [1]. Heterocycles form by far the most of classical divisions of organic chemistry and are of vast use in biologically and industrially. Heterocyclic nucleus imparts an essential function in medicinal chemistry and serves as a key template for the improvement of various therapeutic agents [2]. Imidazoles have in use a sole arrangement in heterocyclic chemistry, and its derivatives have attracted significant interests in recent years for their multipurpose properties in chemistry and pharmacology. It improves pharmacokinetic characteristics of pilot analogues and thus is used as a remedy to optimize solubility and bioavailability parameters of projected unsuccessfully soluble lead molecules. The imidazole derivatives possess extensive spectrum of biological activities such as anti-inflammatory [3], anti-oxidant [4], anti-bacterial [5], anti-cancer [6], anti-tubercular [7] and anti-HIV [8] activities etc.

\section{Literature Review}

Antioxidant participate a fundamental role in the defense mechanism against oxidative damage induced by free radicals and reactive oxygen species (ROS). Reasonable ROS invention and detoxification in a common cellular metabolism is significant to keep the mammalian cells in healthy condition. When a cell fails to detoxify the excessive ROS generated as a result of destructive species or low level of antioxidants, they enter into a state of oxidative stress and are smashed [9]. High levels of ROS can cause injure to cell arrangement, nucleic acids, membrane lipids and proteins [10]. They in addition damage purine and pyrimidine bases of DNA molecule, thus most important to mutation [11]. Oxidative stress on a cell due to high level of ROS can lead to several disorders including cancer, neurodegenerative disorder, atherosclerosis and aging [12]. A lot of studies have recommended that antioxidants that can deactivate free radicals may be of essential interest in the preclusion of vascular diseases and some forms of cancer [13].

Non-steroidal anti-inflammatory drugs (NSAIDs) are commonly approved medications in the earth. They are mainly used for the treatment of pain, fever and inflammation, particularly arthritis [14]. Rheumatic diseases are the most common causes of disability in European countries and NSAIDs are still commonly used remedies. Chronic use might cause several serious adverse effects, the most important one being gastric injury and renal complications. Gastrointestinal (GI) injure from NSAIDs is usually recognized to two factors: local irritation by the straight contact of the free carboxylic acid $(\mathrm{COOH})$ moiety of NSAIDs with GI mucosal cells and decreased tissue prostaglandin invention in tissues [15].

In view of above facts and in extension of our drug development series [16-18], the present work involves the synthesis of a new sequence of imidazole derived Schiff's bases as potential anti-inflammatory and antioxidants. A number of reported effective antioxidant and antiinflammatory activities of Schiff's bases are shown in Figure 1 [19-21].

\section{Results and Discussion}

\section{Chemistry}

Syntheses of title compounds were achieved according to the steps illustrated in Scheme 1. 4-(2-hydroxypropan-2-yl)-2-propyl$1 \mathrm{H}$-imidazole-5-carboxylic acid (1) were ethylated using TMS-Cl and ethanol at room temperature, which upon reaction with excess of hydrazine hydrate afforded the corresponding imidazole hydrazide

*Corresponding authors: Mallesha N, Sri Ram Chem, R \& D Centre, Plot No 31 JCK Industrial Park, Belagola Industrial Estate, Mysore-570016, Karnataka, India, Tel: +91-821-4255588; E-mail: research@sriramchem.com

Rakesh KP, Sri Ram Chem, R \& D Centre, Plot No 31, JCK Industrial Park, Belagola Industrial Estate, Mysore-570016, Karnataka, India, Tel: +91-821-4255588; E-mail: rakeshasg@gmail.com

Received: December 26, 2016; Accepted: April 17, 2017; Published April 20, 2017

Citation: Shantharam CS, Swaroopa M, Darshini N, Mallesha N, Rakesh KP (2017) Synthesis and SAR Studies of Potent Antioxidant and Anti-Inflammatory Activities of Imidazole Derived Schiff Base Analogues. Biochem Anal Biochem 6: 314. doi: 10.4172/2161-1009.1000314

Copyright: () 2017 Shantharam CS, et al. This is an open-access article distributed under the terms of the Creative Commons Attribution License, which permits unrestricted use, distribution, and reproduction in any medium, provided the original author and source are credited. 

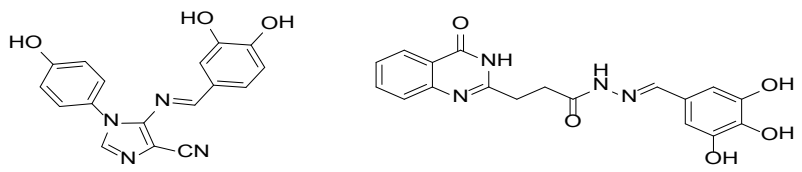<smiles>COc1cc(/C=N/NC(=O)c2ccncc2)cc(OC)c1O</smiles><smiles>O=C(Cc1cccnc1)N/N=C/c1cccc([N+](=O)[O-])c1</smiles>

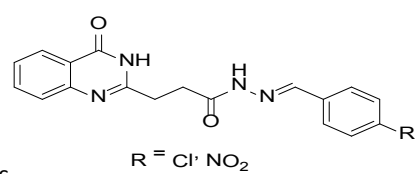

$$
\mathrm{R}=\mathrm{Cl} \cdot \mathrm{NO}_{2}
$$

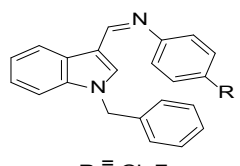

Figure 1: Some of the potent anti-oxidant and anti-inflammatory Schiff's base analogues.
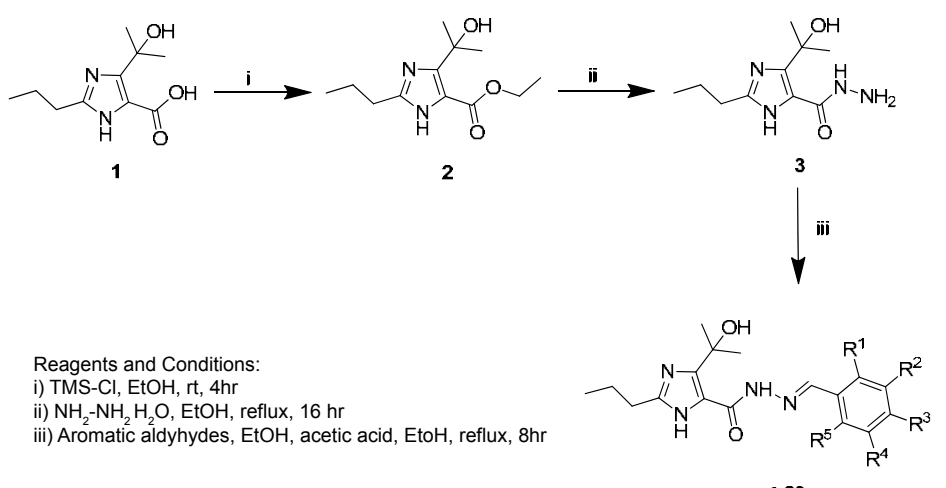

4-23

$$
\begin{array}{cccccccccccc}
\text { Entry } & \mathrm{R}^{1} & \mathrm{R}^{2} & \mathrm{R}^{3} & \mathrm{R}^{4} & \mathrm{R}^{5} & \text { Entry } & \mathrm{R}^{1} & \mathrm{R}^{2} & \mathrm{R}^{3} & \mathrm{R}^{4} & \mathrm{R}^{5} \\
4 & \mathrm{H} & \mathrm{H} & \mathrm{H} & \mathrm{H} & \mathrm{H} & 14 & \mathrm{NO}_{2} & \mathrm{H} & \mathrm{NO}_{2} & \mathrm{H} & \mathrm{H} \\
5 & \mathrm{H} & \mathrm{H} & \mathrm{Cl} & \mathrm{H} & \mathrm{H} & 15 & \mathrm{H} & \mathrm{OH} & \mathrm{OH} & \mathrm{H} & \mathrm{H} \\
6 & \mathrm{H} & \mathrm{H} & \mathrm{NO}_{2} & \mathrm{H} & \mathrm{H} & 16 & \mathrm{H} & \mathrm{OCH}_{3} & \mathrm{OCH}_{3} & \mathrm{H} & \mathrm{H} \\
7 & \mathrm{H} & \mathrm{H} & \mathrm{F} & \mathrm{H} & \mathrm{H} & 17 & \mathrm{H} & \mathrm{Br} & \mathrm{OH} & \mathrm{Br} & \mathrm{H} \\
8 & \mathrm{H} & \mathrm{H} & \mathrm{Br} & \mathrm{H} & \mathrm{H} & 18 & \mathrm{H} & \mathrm{Br} & \mathrm{OH} & \mathrm{H} & \mathrm{H} \\
9 & \mathrm{H} & \mathrm{H} & \mathrm{OCH} & \mathrm{H} & \mathrm{H} & 19 & \mathrm{H} & \mathrm{Br} & \mathrm{OCH}_{3} & \mathrm{H} & \mathrm{H} \\
10 & \mathrm{H} & \mathrm{H} & \mathrm{OH} & \mathrm{H} & \mathrm{H} & 20 & \mathrm{H} & \mathrm{OCH}_{3} & \mathrm{OH} & \mathrm{Br} & \mathrm{H} \\
11 & \mathrm{H} & \mathrm{OCH} & \mathrm{OH} & \mathrm{H} & \mathrm{H} & 21 & \mathrm{Cl} & \mathrm{H} & \mathrm{H} & \mathrm{H} & \mathrm{F} \\
12 & \mathrm{Cl} & \mathrm{H} & \mathrm{Cl} & \mathrm{H} & \mathrm{H} & 22 & \mathrm{H} & \text { OCH }_{3} & \text { OCH } & \text { OCH } & \mathrm{H} \\
13 & \mathrm{~F} & \mathrm{H} & \mathrm{F} & \mathrm{H} & \mathrm{H} & 23 & \mathrm{H} & \text { OH } & \text { OH } & \text { OH } & \mathrm{H}
\end{array}
$$

(3). The Schiff's bases (4-23) were obtained by reacting 3 with several aromatic aldehydes in presence of catalytic amount of glacial acetic acid. All the analogues were obtained in good yield. The structures of all the synthesized compounds as well as intermediates were confirmed by IR, ${ }^{1} \mathrm{HNMR},{ }^{13} \mathrm{CNMR}$ and mass spectral analysis. The formations of ethyl ester (2) were confirmed by the appearance of a triplet at $1.30-1.33 \delta$ for ethyl $\mathrm{CH}_{3}$ and multiplet at $4.30-4.35 \delta$ for ethyl $\mathrm{CH}_{2}$ and absence of $\mathrm{COOH}$ proton peak at $11.80 \delta$ in ${ }^{1} \mathrm{HNMR}$ spectrum. In IR spectra, bands at 3334 and $3220 \mathrm{~cm}^{-1}$ for $\mathrm{NH}_{2}-\mathrm{NH}$ groups indicates the conversion of ethyl esters into hydrazides. The formation of Schiff's bases were confirmed by the presence of absorption at 1604-1635 for imines i.e., $-\mathrm{N}=\mathrm{CH}$ - in IR spectra. The occurrence of all necessary peaks and lack of irrelevant peaks in ${ }^{1} \mathrm{HNMR}$ and ${ }^{13} \mathrm{CNMR}$ confirms the structures.

\section{Biology}

Antioxidant activities: In vitro antioxidant activities of all the synthesized compounds were evaluated by DPPH [22], $\mathrm{ABTS}^{23}$ and $\mathrm{DMPD}^{24}$ cation radical scavenging assay. A lower $\mathrm{IC}_{50}$ value indicated good antioxidant activity. The results were shown in Table 1 . Some of the synthesized compounds showed strong antioxidant activities. 
Citation: Shantharam CS, Swaroopa M, Darshini N, Mallesha N, Rakesh KP (2017) Synthesis and SAR Studies of Potent Antioxidant and AntiInflammatory Activities of Imidazole Derived Schiff Base Analogues. Biochem Anal Biochem 6: 314. doi: 10.4172/2161-1009.1000314

Page 3 of 7

\begin{tabular}{|c|c|c|c|c|}
\hline \multirow{2}{*}{ Entry } & \multicolumn{3}{|c|}{ Antioxidant activity a } & \multirow{2}{*}{ Anti-inflammatory activity ${ }^{a} \mathrm{IC}_{50}(\mu \mathrm{M})$} \\
\hline & DPPH IC ${ }_{50}(\mu \mathrm{M})$ & ABTS $I C_{50}(\mu \mathrm{M})$ & DMPD IC ${ }_{50}(\mu \mathrm{M})$ & \\
\hline 1 & $443 \pm 2.01$ & $424 \pm 1.05$ & $396 \pm 0.46$ & - \\
\hline 2 & $375 \pm 1.06$ & $366 \pm 1.05$ & $358 \pm 0.16$ & - \\
\hline 3 & $380 \pm 1.65$ & $389 \pm 1.56$ & $407 \pm 2.31$ & $407 \pm 2.01$ \\
\hline 4 & $280 \pm 1.26$ & $267 \pm 1.20$ & $286 \pm 1.65$ & $267 \pm 0.56$ \\
\hline 5 & $194 \pm 0.23$ & $177 \pm 1.50$ & $194 \pm 1.89$ & $100 \pm 1.26$ \\
\hline 6 & $172 \pm 0.55$ & $189 \pm 0.26$ & $167 \pm 0.47$ & $77 \pm 0.45$ \\
\hline 7 & $186 \pm 1.02$ & $204 \pm 1.26$ & $192 \pm 1.26$ & $78 \pm 0.16$ \\
\hline 8 & $162 \pm 2.94$ & $172 \pm 2.18$ & $192 \pm 1.26$ & $86 \pm 1.05$ \\
\hline 9 & $110 \pm 1.02$ & $122 \pm 1.46$ & $116 \pm 0.45$ & $174 \pm 1.08$ \\
\hline 10 & $90 \pm 1.04$ & $109 \pm 0.49$ & $103 \pm 0.45$ & $206 \pm 1.04$ \\
\hline 11 & $50 \pm 0.46$ & $72 \pm 1.48$ & $61 \pm 0.46$ & $161 \pm 1.07$ \\
\hline 12 & $182 \pm 1.07$ & $193 \pm 0.14$ & $203 \pm 0.16$ & $46 \pm 1.26$ \\
\hline 13 & $222 \pm 0.23$ & $205 \pm 1.56$ & $205 \pm 1.89$ & $57 \pm 1.45$ \\
\hline 14 & $183 \pm 0.56$ & $193 \pm 0.56$ & $198 \pm 0.56$ & $44 \pm 0.17$ \\
\hline 15 & $57 \pm 0.16$ & $69 \pm 0.18$ & $57 \pm 0.13$ & $173 \pm 0.14$ \\
\hline 16 & $58 \pm 0.18$ & $68 \pm 0.43$ & $64 \pm 0.16$ & $165 \pm 0.19$ \\
\hline 17 & $155 \pm 0.14$ & $143 \pm 1.04$ & $147 \pm 0.15$ & $128 \pm 0.11$ \\
\hline 18 & $151 \pm 0.15$ & $166 \pm 1.06$ & $156 \pm 0.11$ & $122 \pm 0.19$ \\
\hline 19 & $141 \pm 1.26$ & $137 \pm 0.17$ & $142 \pm 0.46$ & $132 \pm 0.14$ \\
\hline 20 & $118 \pm 0.48$ & $132 \pm 1.09$ & $136 \pm 1.09$ & $129 \pm 0.18$ \\
\hline 21 & $196 \pm 1.21$ & $191 \pm 1.04$ & $213 \pm 2.06$ & $54 \pm 0.10$ \\
\hline 22 & $49 \pm 1.08$ & $69 \pm 0.43$ & $54 \pm 0.17$ & $168 \pm 0.12$ \\
\hline 23 & $44 \pm 0.11$ & $55 \pm 0.64$ & $49 \pm 0.47$ & $182 \pm 0.19$ \\
\hline $\mathrm{BHT}$ & $116 \pm 0.88$ & $130 \pm 1.04$ & $127 \pm 0.95$ & - \\
\hline $\mathrm{BHA}$ & $125 \pm 0.88$ & $121 \pm 0.66$ & $131 \pm 0.28$ & - \\
\hline Aspirin & - & - & - & $200 \pm 0.65$ \\
\hline Indomethacin & - & - & - & $112 \pm 0.47$ \\
\hline
\end{tabular}

Table 1: Anti-oxidant and anti-inflammatory activities of the synthesized Imidazole-Schiff's base derivatives.

Compounds 9, 10,11, 15, 16, 22 and 23 showed excellent radical scavenging activities with $\mathrm{IC}_{50}$ values $110 \mu \mathrm{M}, 90 \mu \mathrm{M}, 50 \mu \mathrm{M}, 57 \mu \mathrm{M}$, $58 \mu \mathrm{M}, 49 \mu \mathrm{M}$ and $44 \mu \mathrm{M}$ respectively in DPPH assay much better than the standards BHT $\left(\mathrm{IC}_{50}=116 \mu \mathrm{M}\right)$ and BHA $\left(\mathrm{IC}_{50}=125 \mu \mathrm{M}\right)$. In $\mathrm{ABTS}^{+}$radical scavenging assay, the compounds $9,10,11,15,16,22$ and 23 showed potent antioxidant activity with $\mathrm{IC}_{50}$ values $122 \mu \mathrm{g} /$ $\mathrm{mL}, 109 \mu \mathrm{g} / \mathrm{mL}, 72 \mu \mathrm{g} / \mathrm{mL}, 69 \mu \mathrm{g} / \mathrm{mL}, 68 \mu \mathrm{g} / \mathrm{mL}, 69 \mu \mathrm{g} / \mathrm{mL}$ and $55 \mu \mathrm{g} /$ $\mathrm{mL}$ respectively which is much better than the commercial standards BHT $\left(\mathrm{IC}_{50}=130 \mu \mathrm{M}\right)$ and BHA $\left(\mathrm{IC}_{50}=121 \mu \mathrm{M}\right)$. The compounds 9, 10, $11,15,16,22$ and 23 also exhibited potent antioxidant activity with IC $_{50}$ values $116 \mu \mathrm{M}, 103 \mu \mathrm{M}, 61 \mu \mathrm{M}, 57 \mu \mathrm{M}, 64 \mu \mathrm{M}, 54 \mu \mathrm{M}$ and $49 \mu \mathrm{M}$ respectively which is better than the standards $\mathrm{BHT}\left(\mathrm{IC}_{50}=127 \mu \mathrm{M}\right)$ and BHA $\left(\mathrm{IC}_{50}=131 \mu \mathrm{M}\right)$ in DMPD assay.

In outlook of the above points, compounds having - $\mathrm{OH}$ (phenolic) and $-\mathrm{OCH}_{3}$ (anisole) groups in the phenyl ring $(9,10,11,15,16,22$ and 23) were found to be the most potent antioxidants. In phenyl ring the number of hydroxy and methoxy group increases the activities also increases [16]. The compounds with electron withdrawing $\mathrm{Cl}, \mathrm{F}$, $\mathrm{NO}_{2}$ and $\mathrm{Br}$ substituents $(5-8,12-14$ and 21) showed least antioxidants activity and $\mathrm{IC}_{50}$ values are higher than the standards. The compounds 17-20 were containing both electron donating and withdrawing groups shown that average activity.

Anti-inflammatory activity: In vitro anti-inflammatory activities of the synthesized compounds were also evaluated by using well-known literature procedure in human erythrocytes [23-25]. A huge number of compounds have been recognized exhibiting excellent to moderate activity compared to standard drugs aspirin and indomethacin. $\mathrm{IC}_{50}$ was determined for the compounds showing more than $50 \%$ inhibition concentration (Table 1). The compounds 5, 6, 7, 8, 12, 13, 14 and 21 showed excellent activity with $\mathrm{IC}_{50}$ values $100 \mu \mathrm{M}, 77 \mu \mathrm{M}, 78 \mu \mathrm{M}, 86$ $\mu \mathrm{M}, 46 \mu \mathrm{M}, 57 \mu \mathrm{M}, 44 \mu \mathrm{M}$ and $54 \mu \mathrm{M}$ respectively much better than the standard aspirin $\left(\mathrm{IC}_{50}=200 \mu \mathrm{M}\right)$ and Indomethacin $\left(\mathrm{IC}_{50}=112 \mu \mathrm{M}\right)$. Other compounds 4, 9-11, 15-20, 22 and 23 showed least and moderate activity. It is clear from the results that the compounds bearing electron withdrawing groups $\mathrm{Cl}, \mathrm{F}, \mathrm{NO}_{2}$ and $\mathrm{Br}(5,6,7,8,12,13,14$ and 21) are excellent anti-inflammatory agents and electron donating $(\mathrm{OH}$ and $\mathrm{OCH}_{3}$ ) groups are least anti-inflammatory activity [16]. In phenyl ring the number of electron withdrawing group increases the antiinflammatory activity also increases.

\section{Experimental Data}

\section{General process}

All necessary chemicals and reagents obtained from Merck (India) and Avra Synthesis (India) were used without further purification. Melting points were determined on a Thermonik melting point apparatus (Mumbai) and are uncorrected. FT-IR was performed using a Jasco spectrometer (Japan) using nujol media. ${ }^{1} \mathrm{H}$ NMR $(400 \mathrm{MHz})$ and ${ }^{13} \mathrm{C}$ NMR $(100 \mathrm{MHz})$ spectra were recorded on a Agilent Technologies (USA) using DMSO $\left(d_{6}\right)$ as solvent. High resolution mass spectroscopic analysis was performed on a Bruker MicroTOF QII mass spectrometer in positive mode. Development of the reaction was monitored by aluminum coated TLC plates with the solvent system comprising chloroform/methanol in the ratio 98:02 $\left(\mathrm{R}_{\mathrm{f}}^{\mathrm{a}}\right)$ and 95:05 $\left(\mathrm{R}_{\mathrm{f}}^{\mathrm{b}}\right)$ and the compounds on the TLC plates were detected by under UV light. 
Citation: Shantharam CS, Swaroopa M, Darshini N, Mallesha N, Rakesh KP (2017) Synthesis and SAR Studies of Potent Antioxidant and AntiInflammatory Activities of Imidazole Derived Schiff Base Analogues. Biochem Anal Biochem 6: 314. doi: 10.4172/2161-1009.1000314

Page 4 of 7

\section{Chemistry}

5-(1- Hydroxy-1- methyl-ethyl)- 2-propyl- 3H-imidazole4-carboxylic acid ethyl ester (2)

To a solution of imidazole $(10.6 \mathrm{~g}, 0.05 \mathrm{~mol})$ in ethanol $(100 \mathrm{~mL})$, trimethylsilylchloride $(5.4 \mathrm{~g}, 0.05 \mathrm{~mol})$ was added slowly. The reaction mixture was stirred for $4 \mathrm{hrs}$ to complete the reaction (monitored by TLC). The solvent was removed under reduced pressure and the resultant precipitate was washed with ice cold water and filtered to yield the desired products 2 . Yield $90.9 \%, \mathrm{R}_{\mathrm{f}}^{\mathrm{a}}=0.71, \mathrm{R}_{\mathrm{f}}^{\mathrm{b}}=0.8$, m.p. $184-$ $185^{\circ} \mathrm{C}$, IR $\mathrm{KBr}\left(\mathrm{cm}^{-1}\right): 1750,3214,3315,3510 ;{ }^{1} \mathrm{H}$ NMR (DMSO-d 6 ) $\delta$ ppm: 0.91-0.95 (t, 3H, $\left.\mathrm{CH}_{3}\right) ; 1.30\left(\mathrm{t}, 3 \mathrm{H}, \mathrm{CH}_{3}\right) ; 1.59\left(\mathrm{~s}, 6 \mathrm{H}, 2 \mathrm{CH}_{3}\right)$; 1.68-1.73 (m, $\left.2 \mathrm{H}, \mathrm{CH}_{2}\right) ; 2.62-2.66\left(\mathrm{t}, 2 \mathrm{H}, \mathrm{CH}_{2}\right) ; 4.30-4.35\left(\mathrm{t}, 2 \mathrm{H}, \mathrm{CH}_{2}\right.$ ); $5.84(\mathrm{~s}, 1 \mathrm{H}, \mathrm{OH}) ; 9.9$ (s, 1H, ring NH), HRMS m/z: $241.1750[\mathrm{M}+1]$

5-(1- Hydroxy-1- methyl-ethyl)- 2-propyl- 3H-imidazole- 4carboxylic acid hydrazide (3)

To a solution of $2(10.5 \mathrm{~g}, 0.043 \mathrm{~mol})$ in ethanol $(100 \mathrm{~mL})$, hydrazine hydrate $(2.6 \mathrm{~g}, 0.052 \mathrm{~mol}$,) was added. The reaction mixture was refluxed for $16 \mathrm{hrs}$ for completion of the reaction (monitored by TLC). The solvent was removed under reduced pressure and cooled by adding ice cold water. The resulting precipitate was filtered, washed with cold water and recrystallized from ethanol to get the desired compounds 3 . Yield 85\%, $\mathrm{R}_{\mathrm{f}}^{\mathrm{a}}=0.39, \mathrm{R}_{\mathrm{f}}^{\mathrm{b}}=0.42$, m.p. $201-202^{\circ} \mathrm{C}$, IR $\mathrm{KBr}\left(\mathrm{cm}^{-1}\right): 1614$, 1750, 3214, 3315, 3510; ${ }^{1} \mathrm{H}$ NMR (DMSO-d $) \delta$ ppm: 0.97 (t, 3H, $\mathrm{CH}_{3}$ ); $1.58\left(\mathrm{~s}, 6 \mathrm{H}, 2 \mathrm{CH}_{3}\right) ; 1.67-1.69\left(\mathrm{~m}, 2 \mathrm{H}, \mathrm{CH}_{2}\right) ; 2.58-2.62\left(\mathrm{t}, 2 \mathrm{H}, \mathrm{CH}_{2}\right)$; 4.09-4.11 (d, 2H, NH $)$; $7.09(\mathrm{~s}, 1 \mathrm{H}, \mathrm{OH}) ; 8.37(\mathrm{t}, 1 \mathrm{H}, \mathrm{NH}) ; 8.84(\mathrm{~s}, 1 \mathrm{H}$, ring $\mathrm{NH})$; HRMS m/z, $(\mathrm{M}+1): 227.1758$

\section{General procedure for the synthesis of Schiff's bases (4-23)}

Compounds $3(1 \mathrm{mmol})$ was dissolved in ethanol $(10 \mathrm{~mL} / \mathrm{g}$ of compound) and treated with appropriate aldehydes $(1 \mathrm{mmol})$ in the presence of catalytic amount of glacial acetic acid. The reaction mass were refluxed for $7-8 \mathrm{hr}$ and the end of reaction was monitored by TLC. After end of the reaction, the solvent was removed under reduced pressure and cooled by adding ice cold water. The resulting precipitate was filtered, washed with water and recrystallized from ethanol to obtain the desired Schiff's bases (4-23).

$N^{\prime}$-Benzylidene-4-(2-hydroxyprpan-2-yl)-2-propyl- $1 \mathrm{H}$ imidazole-5-carbohydrazide (4)

Yield 88.40\%, $\mathrm{R}_{\mathrm{f}}^{\mathrm{a}}=0.64, \mathrm{R}_{\mathrm{f}}^{\mathrm{b}}=0.71$, m.p. $189-190^{\circ} \mathrm{C}$, IR KBr $(\mathrm{cm}$ $\left.{ }^{1}\right): 1614,1750,3214,3315,3510 ;{ }^{1} \mathrm{H}$ NMR (DMSO-d $) \delta$ ppm: $0.98(\mathrm{~s}$, $\left.3 \mathrm{H}, \mathrm{CH}_{3}\right), 1.27\left(\mathrm{~s}, 6 \mathrm{H},\left(\mathrm{CH}_{3}\right)_{2}\right), 1.71\left(\mathrm{~m}, 2 \mathrm{H}, \mathrm{CH}_{2}\right), 2.92(\mathrm{t}, J=7.2 \mathrm{~Hz}$, $\left.2 \mathrm{H}, \mathrm{CH}_{2}\right), 7.41-7.85(\mathrm{~m}, 5 \mathrm{H}, \mathrm{Ar}-\mathrm{H}), 7.71(\mathrm{~s}, 1 \mathrm{H},-\mathrm{N}=\mathrm{CH}), 8.14(\mathrm{~s}, 1 \mathrm{H}$, $\mathrm{OH}), 9.70(\mathrm{~s}, 1 \mathrm{H}, \mathrm{NH}), 10.41(\mathrm{~s}, 1 \mathrm{H}, \mathrm{NH}) ;{ }^{13} \mathrm{C}$ NMR (DMSO- $\left.d_{6}\right) \delta \mathrm{ppm}:$ 13.9, 24.1, 29.8, 31.3, 76.2, 128.6, 129.4, 131.1, 133.7, 136.4, 142.8, 143.6, 157.1, 160.1; HRMS m/z: $315.1548[\mathrm{M}+1]$

$N^{\prime}$-(4-Chlorobenzylidene-4-(2-hydroxyprpan-2-yl)-2-propyl$1 \mathrm{H}$-imidazole-5-carbohydrazide (5)

Yield 91.10\%, $\mathrm{R}_{\mathrm{f}}^{\mathrm{a}}=0.52, \mathrm{R}_{\mathrm{f}}^{\mathrm{b}}=0.56$, m.p. $159-160^{\circ} \mathrm{C}, \mathrm{IR} \mathrm{KBr}\left(\mathrm{cm}^{-1}\right)$ : $1619,1768,3215,3320,3560 ;{ }^{1} \mathrm{H}$ NMR (DMSO-d $\left.{ }_{6}\right) \delta \mathrm{ppm}: 0.90(\mathrm{~s}, 3 \mathrm{H}$, $\left.\mathrm{CH}_{3}\right), 1.29\left(\mathrm{~s}, 6 \mathrm{H},\left(\mathrm{CH}_{3}\right)_{2}\right), 1.75\left(\mathrm{~m}, 2 \mathrm{H}, \mathrm{CH}_{2}\right), 2.87(\mathrm{t}, J=6.8 \mathrm{~Hz}, 2 \mathrm{H}$, $\left.\mathrm{CH}_{2}\right), 7.32-7.80(\mathrm{~m}, 4 \mathrm{H}, \mathrm{Ar}-\mathrm{H}), 7.88(\mathrm{~s}, 1 \mathrm{H},-\mathrm{N}=\mathrm{CH}), 9.01(\mathrm{~s}, 1 \mathrm{H}, \mathrm{OH})$, $10.21(\mathrm{~s}, 1 \mathrm{H}, \mathrm{NH}), 11.52(\mathrm{~s}, 1 \mathrm{H}, \mathrm{NH}) ;{ }^{13} \mathrm{C}$ NMR (DMSO- $\left.d_{6}\right) \delta \mathrm{ppm}$ : $13.5,24.4,29.5,31.8,75.9,128.9,129.8,132.1,136.0,136.9,143.1,144.2$, 157.2, 160.1; HRMS m/z: 349.1236 [M+1], $351.6245[\mathrm{M}+3]$

$N^{\prime}$-(4-Nitrobenzylidene-4-(2-hydroxyprpan-2-yl)-2-propyl-1Himidazole-5-carbohydrazide (6)

Yield 86.23\%, $\mathrm{R}_{\mathrm{f}}^{\mathrm{a}}=0.42, \mathrm{R}_{\mathrm{f}}^{\mathrm{b}}=0.50$, m.p. $172-174^{\circ} \mathrm{C}, \mathrm{IR} \mathrm{KBr}\left(\mathrm{cm}^{-1}\right)$ :
$1606,1730,3212,3355,3588 ;{ }^{1} \mathrm{H}$ NMR (DMSO-d $\left.{ }_{6}\right) \delta$ ppm: 0.85 (s, 3H, $\left.\mathrm{CH}_{3}\right), 1.30\left(\mathrm{~s}, 6 \mathrm{H},\left(\mathrm{CH}_{3}\right)_{2}\right), 1.74\left(\mathrm{~m}, 2 \mathrm{H}, \mathrm{CH}_{2}\right), 2.72(\mathrm{t}, J=7.6 \mathrm{~Hz}, 2 \mathrm{H}$, $\left.\mathrm{CH}_{2}\right), 7.60-8.12(\mathrm{~m}, 4 \mathrm{H}, \mathrm{Ar}-\mathrm{H}), 7.88(\mathrm{~s}, 1 \mathrm{H},-\mathrm{N}=\mathrm{CH}), 8.90(\mathrm{~s}, 1 \mathrm{H}, \mathrm{OH})$ 10.09 (s, $1 \mathrm{H}, \mathrm{NH}), 11.12(\mathrm{~s}, 1 \mathrm{H}, \mathrm{NH}) ;{ }^{13} \mathrm{C} \mathrm{NMR}$ (DMSO- $\left.d_{6}\right) \delta \mathrm{ppm}:$ 13.6, 23.9, 28.6, 31.4, 76.2, 124.6, 125.7, 130.1, 136.1, 143.0, 143.9, 151.3, 157.8, 159.9; HRMS m/z: 360.6215 [M+1]

$N^{\prime}$-(4-Fluorobenzylidene-4-(2-hydroxyprpan-2-yl)-2-propyl$1 \mathrm{H}$-imidazole-5-carbohydrazide (7)

Yield 88.10\%, $\mathrm{R}_{\mathrm{f}}^{\mathrm{a}}=0.49, \mathrm{R}_{\mathrm{f}}^{\mathrm{b}}=0.51$, m.p. $168-169^{\circ} \mathrm{C}, \mathrm{IR} \mathrm{KBr}\left(\mathrm{cm}^{-1}\right)$ : $1610,1770,3250,3370,3568$; ${ }^{\mathrm{l}} \mathrm{H}$ NMR (DMSO-d $\left.{ }_{6}\right) \delta \mathrm{ppm}: 0.88(\mathrm{~s}, 3 \mathrm{H}$, $\left.\mathrm{CH}_{3}\right), 1.27\left(\mathrm{~s}, 6 \mathrm{H},\left(\mathrm{CH}_{3}\right)_{2}\right), 1.77\left(\mathrm{~m}, 2 \mathrm{H}, \mathrm{CH}_{2}\right), 2.80(\mathrm{t}, J=8.2 \mathrm{~Hz}, 2 \mathrm{H}$, $\left.\mathrm{CH}_{2}\right), 7.12-7.42(\mathrm{~m}, 4 \mathrm{H}, \mathrm{Ar}-\mathrm{H}), 7.95(\mathrm{~s}, 1 \mathrm{H},-\mathrm{N}=\mathrm{CH}), 8.51(\mathrm{~s}, 1 \mathrm{H}, \mathrm{OH})$ $10.17(\mathrm{~s}, 1 \mathrm{H}, \mathrm{NH}), 11.30(\mathrm{~s}, 1 \mathrm{H}, \mathrm{NH}) ;{ }^{13} \mathrm{C}$ NMR (DMSO- $\left.d_{6}\right) \delta \mathrm{ppm}$ : $12.9,23.8,29.1,31.6,75.8,115.6,128.7,129.1,136.7,142.1,144.5,157.0$, 157.9, 164.1; HRMS m/z: 333.4512 [M+1]

$N^{\prime}$-(4-Bromobenzylidene-4-(2-hydroxyprpan-2-yl)-2-propyl$1 \mathrm{H}$-imidazole-5-carbohydrazide (8)

Yield 86.20\%, $\mathrm{R}_{\mathrm{f}}^{\mathrm{a}}=0.39, \mathrm{R}_{\mathrm{f}}^{\mathrm{b}}=0.42$, m.p. $185-187^{\circ} \mathrm{C}, \mathrm{IR} \mathrm{KBr}\left(\mathrm{cm}^{-1}\right)$ : $1628,1745,3269,3377,3590 ;{ }^{1} \mathrm{H}$ NMR (DMSO-d ) $^{\circ} \delta \mathrm{ppm}: 0.88$ (s, $3 \mathrm{H}$, $\left.\mathrm{CH}_{3}\right), 1.32\left(\mathrm{~s}, 6 \mathrm{H},\left(\mathrm{CH}_{3}\right)_{2}\right), 1.83\left(\mathrm{~m}, 2 \mathrm{H}, \mathrm{CH}_{2}\right), 2.69(\mathrm{t}, J=7.6 \mathrm{~Hz}, 2 \mathrm{H}$, $\left.\mathrm{CH}_{2}\right), 7.55-7.80(\mathrm{~m}, 4 \mathrm{H}, \mathrm{Ar}-\mathrm{H}), 7.99(\mathrm{~s}, 1 \mathrm{H},-\mathrm{N}=\mathrm{CH}), 8.79(\mathrm{~s}, 1 \mathrm{H}, \mathrm{OH})$ $10.56(\mathrm{~s}, 1 \mathrm{H}, \mathrm{NH}), 11.31(\mathrm{~s}, 1 \mathrm{H}, \mathrm{NH}) ;{ }^{13} \mathrm{C} \mathrm{NMR}$ (DMSO- $\left.d_{6}\right) \delta \mathrm{ppm}$ : $13.0,24.1,28.5,30.5,76.0,124.9,125.6,131.1,132.6,136.5,142.0,143.5$, 156.9, 160.1; HRMS m/z: 394.1254 [M+1], $396.5642[\mathrm{M}+3]$

4-(2-Hydroxypropan-2-yl)-N'-(4-methoxybenzylidene--2propyl-1 $H$-imidazole-5-carbohydrazide $(9)$

Yield 85.24\%, $\mathrm{R}_{\mathrm{f}}^{\mathrm{a}}=0.45, \mathrm{R}_{\mathrm{f}}^{\mathrm{b}}=0.51$, m.p. $180-182^{\circ} \mathrm{C}$, IR KBr $(\mathrm{cm}$ $\left.{ }^{1}\right): 1606,1733,3310,3395,3555$; ${ }^{1} \mathrm{H}$ NMR (DMSO-d $\left.{ }_{6}\right) \delta \mathrm{ppm}: 0.92(\mathrm{~s}$ $\left.3 \mathrm{H}, \mathrm{CH}_{3}\right), 1.35\left(\mathrm{~s}, 6 \mathrm{H},\left(\mathrm{CH}_{3}\right)_{2}\right), 1.90\left(\mathrm{~m}, 2 \mathrm{H}, \mathrm{CH}_{2}\right), 2.88(\mathrm{t}, J=6.8 \mathrm{~Hz}$, $\left.2 \mathrm{H}, \mathrm{CH}_{2}\right), 3.78(\mathrm{~s}, 3 \mathrm{H}, \mathrm{OMe}), 7.10-7.82(\mathrm{~m}, 4 \mathrm{H}, \mathrm{Ar}-\mathrm{H}), 7.91(\mathrm{~s}, 1 \mathrm{H}$, $-\mathrm{N}=\mathrm{CH}), 8.56(\mathrm{~s}, 1 \mathrm{H}, \mathrm{OH}), 10.68(\mathrm{~s}, 1 \mathrm{H}, \mathrm{NH}), 11.12(\mathrm{~s}, 1 \mathrm{H}, \mathrm{NH}) ;{ }^{13} \mathrm{C}$ NMR (DMSO- $\left.d_{6}\right) \delta$ ppm: 13.5, 24.3, 29.4, 31.6, 55.6, 75.9, 114.9, 125.5, 130.6, 136.5, 142.8, 144.1, 157.0, 160.3, 163.5; HRMS m/z: 345.1254 $[\mathrm{M}+1]$

$N^{\prime}$-(4-Hydroxybenzylidene-4-(2-hydroxyprpan-2-yl)-2-propyl$1 \mathrm{H}$-imidazole-5-carbohydrazide (10)

Yield 90.56\%, $\mathrm{R}_{\mathrm{f}}^{\mathrm{a}}=0.35, \mathrm{R}_{\mathrm{f}}^{\mathrm{b}}=0.39$, m.p. $166-168^{\circ} \mathrm{C}, \operatorname{IR~} \mathrm{KBr}\left(\mathrm{cm}^{-1}\right)$ : $1610,1740,3260,3380,3565,3590 ;{ }^{1} \mathrm{H}$ NMR (DMSO-d $\left.{ }_{6}\right) \delta$ ppm: 0.90 $\left(\mathrm{s}, 3 \mathrm{H}, \mathrm{CH}_{3}\right), 1.35\left(\mathrm{~s}, 6 \mathrm{H},\left(\mathrm{CH}_{3}\right)_{2}\right), 1.90\left(\mathrm{~m}, 2 \mathrm{H}, \mathrm{CH}_{2}\right), 2.87(\mathrm{t}, J=7.0$ $\left.\mathrm{Hz}, 2 \mathrm{H}, \mathrm{CH}_{2}\right), 6.80-7.45(\mathrm{~m}, 4 \mathrm{H}, \mathrm{Ar}-\mathrm{H}), 7.88(\mathrm{~s}, 1 \mathrm{H},-\mathrm{N}=\mathrm{CH}), 8.90(\mathrm{~s}$, $1 \mathrm{H}, \mathrm{OH}), 9.20$ (s, $1 \mathrm{H}, \mathrm{OH}), 10.61(\mathrm{~s}, 1 \mathrm{H}, \mathrm{NH}), 11.03(\mathrm{~s}, 1 \mathrm{H}, \mathrm{NH}) ;{ }^{13} \mathrm{C}$ NMR (DMSO- $d_{6}$ ) $\delta$ ppm: 13.7, 24.6, 29.5, 31.3, 76.8, 116.9, 126.5, 130.2, 136.1, 142.5, 144.6, 157.5, 160.0, 160.9; HRMS m/z: 331.2364 [M+1]

$N^{\prime}$-(4-Hydroxy-3-methoxybenzylidene)-4-(2-hydroxypropan-2yl)-2-propyl-1H-imidazole-5-carbohydrazide (11)

Yield 82.15\%, $\mathrm{R}_{\mathrm{f}}^{\mathrm{a}}=0.41, \mathrm{R}_{\mathrm{f}}^{\mathrm{b}}=0.47$, m.p. $158-160^{\circ} \mathrm{C}, \mathrm{IR} \mathrm{KBr}\left(\mathrm{cm}^{-1}\right)$ : $1612,1780,3336,3341,3562,3585 ;{ }^{1} \mathrm{H}$ NMR (DMSO-d $\left.{ }_{6}\right) \delta$ ppm: 0.88 $\left(\mathrm{s}, 3 \mathrm{H}, \mathrm{CH}_{3}\right), 1.31\left(\mathrm{~s}, 6 \mathrm{H},\left(\mathrm{CH}_{3}\right)_{2}\right), 1.86\left(\mathrm{~m}, 2 \mathrm{H}, \mathrm{CH}_{2}\right), 2.81(\mathrm{t}, J=7.8 \mathrm{~Hz}$, $\left.2 \mathrm{H}, \mathrm{CH}_{2}\right), 3.78(\mathrm{~s}, 3 \mathrm{H}, \mathrm{OMe}), 6.91-7.62(\mathrm{~m}, 3 \mathrm{H}, \mathrm{Ar}-\mathrm{H}), 8.02(\mathrm{~s}, 1 \mathrm{H}$ $-\mathrm{N}=\mathrm{CH}), 9.12(\mathrm{~s}, 1 \mathrm{H}, \mathrm{OH}), 9.45(\mathrm{~s}, 1 \mathrm{H}, \mathrm{OH}), 10.37(\mathrm{~s}, 1 \mathrm{H}, \mathrm{NH}), 11.16$ $(\mathrm{s}, 1 \mathrm{H}, \mathrm{NH}) ;{ }^{13} \mathrm{C}$ NMR (DMSO- $\left.d_{6}\right) \delta \mathrm{ppm}: 14.1,25.2,30.3,31.0,56.2$, 76.1, 112.1, 117.0, 122.6, 130.6, 136.1, 143.5, 144.3, 149.8, 151.6, 157.6, 160.1; HRMS m/z: $361.4562[\mathrm{M}+1]$

$N^{\prime}$-(2,4-dichlorobenzylidene)-4-(2-hydroxypropan-2-yl)-2propyl-1H-imidazole-5-carbohydrazide (12)

Yield 87.28\%, $\mathrm{R}_{\mathrm{f}}^{\mathrm{a}}=0.43, \mathrm{R}_{\mathrm{f}}^{\mathrm{b}}=0.50$, m.p. $175-176^{\circ} \mathrm{C}, \mathrm{IR} \mathrm{KBr}\left(\mathrm{cm}^{-1}\right)$ : 
Citation: Shantharam CS, Swaroopa M, Darshini N, Mallesha N, Rakesh KP (2017) Synthesis and SAR Studies of Potent Antioxidant and AntiInflammatory Activities of Imidazole Derived Schiff Base Analogues. Biochem Anal Biochem 6: 314. doi: 10.4172/2161-1009.1000314

Page 5 of 7

$1622,1758,3312,3379,3545 ;{ }^{1} \mathrm{H}$ NMR (DMSO-d $) \delta$ ppm: $0.89(\mathrm{~s}, 3 \mathrm{H}$, $\left.\mathrm{CH}_{3}\right), 1.35\left(\mathrm{~s}, 6 \mathrm{H},\left(\mathrm{CH}_{3}\right)_{2}\right), 1.80\left(\mathrm{~m}, 2 \mathrm{H}, \mathrm{CH}_{2}\right), 2.84(\mathrm{t}, J=6.8 \mathrm{~Hz}, 2 \mathrm{H}$, $\left.\mathrm{CH}_{2}\right), 7.20-7.82(\mathrm{~m}, 3 \mathrm{H}, \mathrm{Ar}-\mathrm{H}), 8.10(\mathrm{~s}, 1 \mathrm{H},-\mathrm{N}=\mathrm{CH}), 9.52(\mathrm{~s}, 1 \mathrm{H}, \mathrm{OH})$, $10.52(\mathrm{~s}, 1 \mathrm{H}, \mathrm{NH}), 11.13(\mathrm{~s}, 1 \mathrm{H}, \mathrm{NH}) ;{ }^{13} \mathrm{C}$ NMR $\left(\mathrm{DMSO}-d_{6}\right) \delta \mathrm{ppm}: 13.3$, $24.5,30.6,31.4,76.3,126.9,128.2,129.4,129.9,131.4,132.0,136.1,140.5$, 142.3, 157.6, 160.3; HRMS m/z: 384.1546 [M+1], 386.4569 [M+3]

$N^{\prime}$-(2,4-difluorobenzylidene)-4-(2-hydroxypropan-2-yl)-2propyl-1H-imidazole-5-carbohydrazide (13)

Yield $84.20 \%, \mathrm{R}_{\mathrm{f}}^{\mathrm{a}}=0.46, \mathrm{R}_{\mathrm{f}}^{\mathrm{b}}=0.52$, m.p. $181-182{ }^{\circ} \mathrm{C}, \mathrm{IR} \mathrm{KBr}(\mathrm{cm}$ $\left.{ }^{1}\right): 1630,1755,3324,3318,3569 ;{ }^{1} \mathrm{H}$ NMR (DMSO-d $) \delta$ ppm: 0.85 $\left(\mathrm{s}, 3 \mathrm{H}, \mathrm{CH}_{3}\right), 1.32\left(\mathrm{~s}, 6 \mathrm{H},\left(\mathrm{CH}_{3}\right)_{2}\right), 1.83\left(\mathrm{~m}, 2 \mathrm{H}, \mathrm{CH}_{2}\right), 2.79(\mathrm{t}, J=7.0$ $\left.\mathrm{Hz}, 2 \mathrm{H}, \mathrm{CH}_{2}\right), 6.92$ (s, 1H, Ar-H), 7.13-7.70 (m, 2H, Ar-H), 7.84 (s, $1 \mathrm{H},-\mathrm{N}=\mathrm{CH}), 8.99(\mathrm{~s}, 1 \mathrm{H}, \mathrm{OH}), 10.60(\mathrm{~s}, 1 \mathrm{H}, \mathrm{NH}), 11.17(\mathrm{~s}, 1 \mathrm{H}, \mathrm{NH})$; ${ }^{13} \mathrm{C}$ NMR (DMSO- $d_{6}$ ) $\delta$ ppm: 14.3, 24.9, 29.5, 31.1, 76.1, 111.3, 112.9, 113.4, 132.1, 136.4, 142.8, 143.6, 157.2, 160.3, 161.4, 163.2; HRMS m/z: $351.4521[\mathrm{M}+1]$

$N^{\prime}$-(2,4-Dinitrobenzylidene)-4-(2-hydroxypropan-2-yl)-2propyl-1H-imidazole-5-carbohydrazide (14)

Yield 81.98\%, $\mathrm{R}_{\mathrm{f}}^{\mathrm{a}}=0.51, \mathrm{R}_{\mathrm{f}}^{\mathrm{b}}=0.57$, m.p. $191-192{ }^{\circ} \mathrm{C}, \mathrm{IR} \mathrm{KBr}(\mathrm{cm}$ $\left.{ }^{1}\right): 1622,1768,3375,3398,3514 ;{ }^{1} \mathrm{H}$ NMR (DMSO-d $\left.{ }_{6}\right) \delta$ ppm: 0.89 $\left(\mathrm{s}, 3 \mathrm{H}, \mathrm{CH}_{3}\right), 1.29\left(\mathrm{~s}, 6 \mathrm{H},\left(\mathrm{CH}_{3}\right)_{2}\right), 1.77\left(\mathrm{~m}, 2 \mathrm{H}, \mathrm{CH}_{2}\right), 2.86(\mathrm{t}, J=7.8$ $\left.\mathrm{Hz}, 2 \mathrm{H}, \mathrm{CH}_{2}\right), 7.92(\mathrm{~s}, 1 \mathrm{H}, \mathrm{N}=\mathrm{CH}), 8.20-840(\mathrm{~m}, 2 \mathrm{H}, \mathrm{Ar}-\mathrm{H}), 8.84$ (s, 1H, Ar-H), 9.99 (s, 1H, OH), 10.29 (s, 1H, NH), 11.03 (s, 1H, NH); ${ }^{13} \mathrm{C}$ NMR (DMSO- $d_{6}$ ) $\delta$ ppm: 13.9, 23.9, 29.3, 31.5, 76.4, 120.5, 130.4, 131.2, 133.1, 136.1, 142.4, 143.9, 148.2, 151.6, 157.2, 160.3; HRMS m/z: $405.3542[\mathrm{M}+1]$

$N^{\prime}$-(3,4-Dihydroxybenzylidene)-4-(2-hydroxypropan-2-yl)-2propyl-1H-imidazole-5-carbohydrazide (15)

Yield 86.77\%, $\mathrm{R}_{\mathrm{f}}^{\mathrm{a}}=0.32, \mathrm{R}_{\mathrm{f}}^{\mathrm{b}}=0.37$, m.p. $166-167^{\circ} \mathrm{C}, \mathrm{IR} \mathrm{KBr}\left(\mathrm{cm}^{-1}\right)$ : 1610, 1710, 3318, 3374, 3520, 3599; ${ }^{1} \mathrm{H}$ NMR (DMSO-d $) \delta$ ppm: 0.84 $\left(\mathrm{s}, 3 \mathrm{H}, \mathrm{CH}_{3}\right), 1.22\left(\mathrm{~s}, 6 \mathrm{H},\left(\mathrm{CH}_{3}\right)_{2}\right), 1.82\left(\mathrm{~m}, 2 \mathrm{H}, \mathrm{CH}_{2}\right), 2.78(\mathrm{t}, J=7.4$ $\left.\mathrm{Hz}, 2 \mathrm{H}, \mathrm{CH}_{2}\right), 6.80-7.45(\mathrm{~m}, 3 \mathrm{H}, \mathrm{Ar}-\mathrm{H}), 7.88(\mathrm{~s}, 1 \mathrm{H},-\mathrm{N}=\mathrm{CH}), 8.84$ (s, 1H, 0H), $9.57(\mathrm{~s}, 2 \mathrm{H}, \mathrm{OH}), 10.56(\mathrm{~s}, 1 \mathrm{H}, \mathrm{NH}), 11.09(\mathrm{~s}, 1 \mathrm{H}, \mathrm{NH})$; ${ }^{13} \mathrm{C}$ NMR (DMSO- $d_{6}$ ) $\delta$ ppm: 13.8, 23.7, 29.3, 31.0, 76.1, 116.2, 118.3, 123.5, 131.1, 136.3, 142.7, 143.1, 148.1, 151.0, 157.3, 160.7; HRMS m/z: $347.6524[\mathrm{M}+1]$

$N^{\prime}$-(3,4-Dimethoxybenzylidene)-4-(2-hydroxypropan-2-yl)-2propyl-1H-imidazole-5-carbohydrazide (16)

Yield 83.15\%, $\mathrm{R}_{\mathrm{f}}^{\mathrm{a}}=0.44, \mathrm{R}_{\mathrm{f}}^{\mathrm{b}}=0.51$, m.p. $157-158^{\circ} \mathrm{C}$, IR KBr $(\mathrm{cm}$ $\left.{ }^{1}\right): 1612,1770,3317,3384,3566 ;{ }^{1} \mathrm{H}$ NMR (DMSO-d $) ~ \delta$ ppm: $0.89(\mathrm{~s}$, $\left.3 \mathrm{H}, \mathrm{CH}_{3}\right), 1.20\left(\mathrm{~s}, 6 \mathrm{H},\left(\mathrm{CH}_{3}\right)_{2}\right), 1.90\left(\mathrm{~m}, 2 \mathrm{H}, \mathrm{CH}_{2}\right), 2.90(\mathrm{t}, J=6.6 \mathrm{~Hz}$, $\left.2 \mathrm{H}, \mathrm{CH}_{2}\right), 3.82(\mathrm{~s}, 6 \mathrm{H}, 2 \mathrm{OMe}), 6.92-7.51(\mathrm{~m}, 3 \mathrm{H}, \mathrm{Ar}-\mathrm{H}), 7.93(\mathrm{~s}, 1 \mathrm{H}$, $-\mathrm{N}=\mathrm{CH}), 8.99$ (s, 1H, OH), $10.12(\mathrm{~s}, 1 \mathrm{H}, \mathrm{NH}), 11.16(\mathrm{~s}, 1 \mathrm{H}, \mathrm{NH}) ;{ }^{13} \mathrm{C}$ NMR (DMSO- $d_{6}$ ) $\delta$ ppm: 13.9, 23.8 29.4, 31.4, 56.4, 76.7, 109.3, 111.3, 122.6, 130.8, 136.8, 142.8, 144.2, 150.1, 152.4, 157.8, 160.4; HRMS m/z: $375.2654[\mathrm{M}+1]$

$N^{\prime}$-(3,5-Dibromo-4-hydroxybenzylidene)-4-(2-hydroxypropan2-yl)-2-propyl-1H-imidazole-5-carbohydrazide (17)

Yield $85.10 \%, \mathrm{R}_{\mathrm{f}}^{\mathrm{a}}=0.40, \mathrm{R}_{\mathrm{f}}^{\mathrm{b}}=0.44$, m.p. $168-169^{\circ} \mathrm{C}$, IR KBr $(\mathrm{cm}$ $\left.{ }^{1}\right): 1608,1778,3330,3398,3547 ;{ }^{1} \mathrm{H}$ NMR (DMSO-d $\left.{ }_{6}\right) \delta$ ppm: 0.93 $\left(\mathrm{s}, 3 \mathrm{H}, \mathrm{CH}_{3}\right), 1.28\left(\mathrm{~s}, 6 \mathrm{H},\left(\mathrm{CH}_{3}\right)_{2}\right), 1.94\left(\mathrm{~m}, 2 \mathrm{H}, \mathrm{CH}_{2}\right), 2.84(\mathrm{t}, J=6.8$ $\left.\mathrm{Hz}, 2 \mathrm{H}, \mathrm{CH}_{2}\right), 7.60-7.72(\mathrm{~m}, 2 \mathrm{H}, \mathrm{Ar}-\mathrm{H}), 7.88(\mathrm{~s}, 1 \mathrm{H},-\mathrm{N}=\mathrm{CH}), 8.78$ (s, $1 \mathrm{H}, \mathrm{OH}), 9.45(\mathrm{~s}, 1 \mathrm{H}, \mathrm{OH}), 10.19(\mathrm{~s}, 1 \mathrm{H}, \mathrm{NH}), 11.12(\mathrm{~s}, 1 \mathrm{H}, \mathrm{NH})$; ${ }^{13} \mathrm{C}$ NMR (DMSO- $d$ ) $\delta$ ppm: 13.4, $23.629 .5,31.3,76.3,110.3,129.3$, 130.6, 136.8, 142.8, 145.8, 157.2, 158.1, 160.6; HRMS m/z: 489.2314 $[\mathrm{M}+1], 491.2654[\mathrm{M}+3]$
$N^{\prime}$-(3-Bromo-4-hydroxybenzylidene)-4-(2-hydroxypropan-2yl)-2-propyl-1H-imidazole-5-carbohydrazide (18)

Yield 87.10\%, $\mathrm{R}_{\mathrm{f}}^{\mathrm{a}}=0.46, \mathrm{R}_{\mathrm{f}}^{\mathrm{b}}=0.51$, m.p. $174-175^{\circ} \mathrm{C}$, IR $\mathrm{KBr}(\mathrm{cm}$ $\left.{ }^{1}\right): 1616,1788,3320,3399,3565 ;{ }^{1} \mathrm{H}$ NMR (DMSO-d $\left.{ }_{6}\right) \delta$ ppm: $0.89(\mathrm{~s}$, $\left.3 \mathrm{H}, \mathrm{CH}_{3}\right), 1.33\left(\mathrm{~s}, 6 \mathrm{H},\left(\mathrm{CH}_{3}\right)_{2}\right), 1.87\left(\mathrm{~m}, 2 \mathrm{H}, \mathrm{CH}_{2}\right), 2.74(\mathrm{t}, J=8.0 \mathrm{~Hz}$, $\left.2 \mathrm{H}, \mathrm{CH}_{2}\right), 6.90-7.77(\mathrm{~m}, 3 \mathrm{H}, \mathrm{Ar}-\mathrm{H}), 7.97(\mathrm{~s}, 1 \mathrm{H},-\mathrm{N}=\mathrm{CH}), 8.88(\mathrm{~s}, 1 \mathrm{H}$, $\mathrm{OH}), 9.45$ (s, 1H, OH), $10.82(\mathrm{~s}, 1 \mathrm{H}, \mathrm{NH}), 11.13(\mathrm{~s}, 1 \mathrm{H}, \mathrm{NH}) ;{ }^{13} \mathrm{C}$ NMR (DMSO-d $) \delta$ ppm: 14.4, 24.1 29.8, 31.6, 76.4, 113.3, 118.6, 128.4, 129.4, 130.4, 136.7, 142.7, 145.4, 157.4, 158.4, 160.9; HRMS m/z: 410.2654 $[\mathrm{M}+1], 412.2654[\mathrm{M}+3]$

$N^{\prime}$-(3-Bromo-4-methoxybenzylidene)-4-(2-hydroxypropan-2yl)-2-propyl-1 $H$-imidazole-5-carbohydrazide (19)

Yield $88.17 \%, \mathrm{R}_{\mathrm{f}}^{\mathrm{a}}=0.51, \mathrm{R}_{\mathrm{f}}^{\mathrm{b}}=0.57$, m.p. $179-181^{\circ} \mathrm{C}$, IR KBr $(\mathrm{cm}$ $\left.{ }^{1}\right): 1607,1729,3314,3347,3558$; ${ }^{1} \mathrm{H}$ NMR (DMSO-d $\left.{ }_{6}\right) \delta$ ppm: $0.91(\mathrm{~s}$, $\left.3 \mathrm{H}, \mathrm{CH}_{3}\right), 1.37\left(\mathrm{~s}, 6 \mathrm{H},\left(\mathrm{CH}_{3}\right)_{2}\right), 1.88\left(\mathrm{~m}, 2 \mathrm{H}, \mathrm{CH}_{2}\right), 2.82(\mathrm{t}, J=7.2 \mathrm{~Hz}$, $\left.2 \mathrm{H}, \mathrm{CH}_{2}\right), 3.81(\mathrm{~s}, 3 \mathrm{H}, \mathrm{OMe}), 6.92-7.71(\mathrm{~m}, 3 \mathrm{H}, \mathrm{Ar}-\mathrm{H}), 7.89(\mathrm{~s}, 1 \mathrm{H}$, $-\mathrm{N}=\mathrm{CH}), 9.10(\mathrm{~s}, 1 \mathrm{H}, \mathrm{OH}), 10.22(\mathrm{~s}, 1 \mathrm{H}, \mathrm{NH}), 11.14(\mathrm{~s}, 1 \mathrm{H}, \mathrm{NH}) ;{ }^{13} \mathrm{C}$ NMR (DMSO- $d_{6}$ ) $\delta$ ppm: 13.5, 24.3 29.7, 31.3, 56.4, 76.5, 111.3, 112.6, $128.1,129.0,129.4,136.0,142.3,144.1,157.1,158.3,160.6 ; \mathrm{HRMS} \mathrm{m} / \mathrm{z}$ $424.1264[\mathrm{M}+1], 426.4597[\mathrm{M}+3]$

$N^{\prime}-(3$ - B romo-4-hydroxy-5-methoxybenzylidene)4-(2-hydroxypropan-2-yl)-2-propyl- $1 H$-imidazole-5carbohydrazide $(20)$

Yield 89.27\%, $\mathrm{R}_{\mathrm{f}}^{\mathrm{a}}=0.42, \mathrm{R}_{\mathrm{f}}^{\mathrm{b}}=0.47$, m.p. $165-168^{\circ} \mathrm{C}$, IR KBr $(\mathrm{cm}$ $\left.{ }^{1}\right): 1611,1735,3322,3354,3560$; ${ }^{1} \mathrm{H}$ NMR (DMSO-d $\left.{ }_{6}\right) \delta$ ppm: $0.87(\mathrm{~s}$, $\left.3 \mathrm{H}, \mathrm{CH}_{3}\right), 1.34\left(\mathrm{~s}, 6 \mathrm{H},\left(\mathrm{CH}_{3}\right)_{2}\right), 1.84\left(\mathrm{~m}, 2 \mathrm{H}, \mathrm{CH}_{2}\right), 2.77(\mathrm{t}, J=7.0 \mathrm{~Hz}$, $\left.2 \mathrm{H}, \mathrm{CH}_{2}\right), 3.77(\mathrm{~s}, 3 \mathrm{H}, \mathrm{OMe}), 7.32-7.42(\mathrm{~m}, 2 \mathrm{H}, \mathrm{Ar}-\mathrm{H}), 7.87(\mathrm{~s}, 1 \mathrm{H}$, $-\mathrm{N}=\mathrm{CH}), 9.10(\mathrm{~s}, 1 \mathrm{H}, \mathrm{OH}), 9.88(\mathrm{~s}, 1 \mathrm{H}, \mathrm{OH}), 10.21(\mathrm{~s}, 1 \mathrm{H}, \mathrm{NH}), 11.22$ $(\mathrm{s}, 1 \mathrm{H}, \mathrm{NH}) ;{ }^{13} \mathrm{C}$ NMR (DMSO- $\left.d_{6}\right) \delta \mathrm{ppm}: 13.2,24.129 .6,31.8,56.2$, 76.1, 111.0, 114.4, 122.1, 129.9, 136.7, 142.1, 143.4, 145.6, 153.6, 157.4, 159.9; HRMS m/z: 440.1654 [M+1], $442.1564[\mathrm{M}+3]$

$N^{\prime}$-(2-Chloro-6-fluorobenzylidene)-4-(2-hydroxypropan-2-yl)2-propyl-1H-imidazole-5-carbohydrazide (21)

Yield 86.38\%, $\mathrm{R}_{\mathrm{f}}^{\mathrm{a}}=0.52, \mathrm{R}_{\mathrm{f}}^{\mathrm{b}}=0.59$, m.p. $170-171^{\circ} \mathrm{C}, \mathrm{IR} \mathrm{KBr}(\mathrm{cm}$ $\left.{ }^{1}\right): 1602,1758,3310,3359,3566$; ${ }^{1} \mathrm{H}$ NMR (DMSO-d $)$ ) $\delta$ ppm: $0.89(\mathrm{~s}$, $\left.3 \mathrm{H}, \mathrm{CH}_{3}\right), 1.39\left(\mathrm{~s}, 6 \mathrm{H},\left(\mathrm{CH}_{3}\right)_{2}\right), 1.89\left(\mathrm{~m}, 2 \mathrm{H}, \mathrm{CH}_{2}\right), 2.90(\mathrm{t}, J=5.8 \mathrm{~Hz}$, $\left.2 \mathrm{H}, \mathrm{CH}_{2}\right), 7.22-7.49(\mathrm{~m}, 3 \mathrm{H}, \mathrm{Ar}-\mathrm{H}), 7.90(\mathrm{~s}, 1 \mathrm{H},-\mathrm{N}=\mathrm{CH}), 9.28(\mathrm{~s}, 1 \mathrm{H}$, $\mathrm{OH}), 10.12(\mathrm{~s}, 1 \mathrm{H}, \mathrm{NH}), 11.01(\mathrm{~s}, 1 \mathrm{H}, \mathrm{NH}) ;{ }^{13} \mathrm{C}$ NMR (DMSO- $\left.d_{6}\right) \delta$ ppm: 13.8, 24.3 29.1, 31.0, 76.0, 113.8 118.4, 125.7, 134.5, 135.4, 136.9, 142.0, 143.7, 156.5, 160.5, 161.5; HRMS m/z: 367.4521 [M+1], 369.2451 $[\mathrm{M}+3]$

4-(2-hydroxypropan-2-yl)-2-propyl- $N^{\prime}$-(3,4,5-trimethoxybenzylidene)-1 $\mathrm{H}$-imidazole-5-carbohydrazide (22)

Yield $85.41 \%, \mathrm{R}_{\mathrm{f}}^{\mathrm{a}}=0.42, \mathrm{R}_{\mathrm{f}}^{\mathrm{b}}=0.48$, m.p. $168-169^{\circ} \mathrm{C}$, IR $\mathrm{KBr}(\mathrm{cm}$ $\left.{ }^{1}\right): 1610,1766,3352,3369,3588$; ${ }^{1} \mathrm{H}$ NMR (DMSO-d $\left.\mathrm{d}_{6}\right) \delta$ ppm: $0.88(\mathrm{~s}$ $\left.3 \mathrm{H}, \mathrm{CH}_{3}\right), 1.36\left(\mathrm{~s}, 6 \mathrm{H},\left(\mathrm{CH}_{3}\right)_{2}\right), 1.84\left(\mathrm{~m}, 2 \mathrm{H}, \mathrm{CH}_{2}\right), 2.77(\mathrm{t}, J=8.2 \mathrm{~Hz}$, $\left.2 \mathrm{H}, \mathrm{CH}_{2}\right), 3.82(\mathrm{~s}, 9 \mathrm{H}, 3 \mathrm{OMe}), 7.12-7.18(\mathrm{~m}, 2 \mathrm{H}, \mathrm{Ar}-\mathrm{H}), 7.99(\mathrm{~s}, 1 \mathrm{H}$, $-\mathrm{N}=\mathrm{CH}), 9.38(\mathrm{~s}, 1 \mathrm{H}, \mathrm{OH}), 10.11(\mathrm{~s}, 1 \mathrm{H}, \mathrm{NH}), 11.56(\mathrm{~s}, 1 \mathrm{H}, \mathrm{NH}) ;{ }^{13} \mathrm{C}$ NMR (DMSO- $d_{6}$ ) $\delta$ ppm: 13.2, 24.8 29.7, 31.6, 56.2, 60.6, 76.7, 104.2, $128.4,136.4,141.5,142.4,144.9,153.5,156.0,160.4 ;$ HRMS m/z: $405.1265[\mathrm{M}+1]$

4 - ( 2 - hyd roxy propan - 2 - yl) - 2 - propyl- $N^{\prime}-(3,4,5-$ trihydroxybenzylidene)- $1 \mathrm{H}$-imidazole-5-carbohydrazide (23)

Yield 84.09\%, $\mathrm{R}_{\mathrm{f}}^{\mathrm{a}}=0.30, \mathrm{R}_{\mathrm{f}}^{\mathrm{b}}=0.34$, m.p. $174-175^{\circ} \mathrm{C}$, IR $\mathrm{KBr}(\mathrm{cm}$ $\left.{ }^{1}\right): 1615,1719,3349,3359,3562 ;{ }^{1} \mathrm{H}$ NMR (DMSO-d $\left.{ }_{6}\right) \delta$ ppm: 0.84 
Citation: Shantharam CS, Swaroopa M, Darshini N, Mallesha N, Rakesh KP (2017) Synthesis and SAR Studies of Potent Antioxidant and AntiInflammatory Activities of Imidazole Derived Schiff Base Analogues. Biochem Anal Biochem 6: 314. doi: 10.4172/2161-1009.1000314

Page 6 of 7

$\left(\mathrm{s}, 3 \mathrm{H}, \mathrm{CH}_{3}\right), 1.30\left(\mathrm{~s}, 6 \mathrm{H},\left(\mathrm{CH}_{3}\right)_{2}\right), 1.80\left(\mathrm{~m}, 2 \mathrm{H}, \mathrm{CH}_{2}\right), 2.81(\mathrm{t}, J=7.6$ $\left.\mathrm{Hz}, 2 \mathrm{H}, \mathrm{CH}_{2}\right), 5.01(\mathrm{~s}, 1 \mathrm{H}, \mathrm{OH}), 6.88-7.10(\mathrm{~m}, 2 \mathrm{H}, \mathrm{Ar}-\mathrm{H}), 7.78(\mathrm{~s}, 1 \mathrm{H}$, $-\mathrm{N}=\mathrm{CH}), 8.12(\mathrm{~s}, 2 \mathrm{H}, 2 \mathrm{OH}), 9.38(\mathrm{~s}, 1 \mathrm{H}, \mathrm{OH}), 10.11(\mathrm{~s}, 1 \mathrm{H}, \mathrm{NH}), 11.56$ $(\mathrm{s}, 1 \mathrm{H}, \mathrm{NH}) ;{ }^{13} \mathrm{C}$ NMR (DMSO- $\left.d_{6}\right) \delta \mathrm{ppm}: 13.1,24.5$ 29.6, 31.0, 76.4, 108.2, 129.4, 136.1, 138.5, 141.7, 143.3, 146.1, 157.5, 160.1; HRMS m/z: $363.1265[\mathrm{M}+1]$

\section{Biological Screening}

\section{Antioxidant activities}

DPPH (1,1-diphenyl-2-picryl-hydrazyl) test [22]: The radical scavenging activity of DPPH free radicals by synthesized compounds was determined according to the reported method. Briefly, $50 \mu \mathrm{L}$ of test compounds was mixed at different concentrations $(20-100 \mu \mathrm{M} /$ $\mathrm{mL}$ ) with $1 \mathrm{~mL}$ of $0.1 \mathrm{mM} \mathrm{DPPH}$ in methanol solution and $450 \mu \mathrm{L}$ of 50 $\mathrm{mM}$ Tris $\mathrm{HCl}$ buffer ( $\mathrm{pH}$ 7.4) and as an experimental control methanol $(50 \mu \mathrm{L})$ only was used. After $30 \mathrm{~min}$ of incubation at room temperature and reading was recorded spectrophotometrically at $517 \mathrm{~nm}$.

Percent inhibition was calculated from the following equation:

$\%$ Inhibition $=\left[\frac{\text { Absorbance of control }- \text { Absorbance of test sample }}{\text { Absorbance of control }}\right] \times 100$

ABTS (2,2-azinobis-(3-ethylbenzothiazoline-6-sufonic acid) test: The ability of the test sample to scavenge $\mathrm{ABTS}^{+}$radical cation was determined according to the literature method [23]. The ABTS ${ }^{+}$radical cation was pregenerated by mixing $7 \mathrm{mM} \mathrm{ABTS}^{+}$stock solution with $2.45 \mathrm{mM}$ potassium persulfate and incubating for $12-16 \mathrm{hrs}$ in the dark room at normal temperature till the colors changes from green to blue, then the absorbance was stable. Using distilled water, the absorbance of the ABTS ${ }^{+}$solution was equilibrated to $0.70( \pm 0.02)$, then $2 \mathrm{~mL}$ was mixed with different concentration of the test sample $(20$ to $100 \mu \mathrm{g} /$ $\mathrm{mL}$ ) and after 6-8 $\mathrm{min}$ the absorbance was measured at $734 \mathrm{~nm}$.

The scavenging effect of $\mathrm{ABTS}^{+}$radical was calculated using the following formula:

$\mathrm{ABTS}^{+}$scavenging effect $(\%)=\left[\left(\mathrm{A}_{\mathrm{c}}-\mathrm{A}_{\mathrm{s}}\right) / \mathrm{A}_{\mathrm{c}}\right] \times 100$

Where, $\mathrm{A}_{c}$ is the initial concentration of the ABTS ${ }^{+}$and $\mathrm{A}_{\mathrm{s}}$ is the absorbance of the remaining concentration of ABTS $^{+}$in the presence of compounds.

DMPD ( $N, N$-dimethyl-p-phenylenediamine) test: The DMPD radical scavenging ability of synthesized compounds was determined by the Fogliano et al., method [24] with slight modification. The $5 \mathrm{~mL}$ solution of DMPD $(105 \mathrm{mg})$ in distilled water was prepared. Then, $1 \mathrm{~mL}$ of this solution was added to $100 \mathrm{~mL}$ of $0.1 \mathrm{M}$ acetate buffer ( $\mathrm{pH} 5.3$ ). $0.3 \mathrm{~mL}$ ferric chloride $(0.05 \mathrm{M})$ was to the solution to produce DMPD ${ }^{+}$. Different concentrations of standard antioxidants or synthesized compounds $(20-100 \mu \mathrm{g} / \mathrm{mL})$ were added, and the total volume was adjusted to $1 \mathrm{~mL}$ with distilled water. $1 \mathrm{~mL}$ of the $\mathrm{DMPD}^{++}$solution was added to the reaction mixture. The reaction mixtures were incubated in the dark for $15 \mathrm{~min}$. The absorbance was measured at $505 \mathrm{~nm}$.

$\%$ Inhibition $=\left[\frac{\text { Absorbance of control }- \text { Absorbance of test sample }}{\text { Absorbance of control }}\right] \times 100$

\section{Anti-inflammatory activity}

Human erythrocyte suspension: The human blood was collected from a healthy volunteer who had not taken any NSAIDs for 2 weeks prior to the experiment and collected in heparinzed vacutainer. The collected healthy human blood was washed $0.9 \%$ saline and centrifuged for 10 minutes at $3000 \mathrm{rpm}$. The packed cells were washed with $0.9 \%$ saline and $40 \% \mathrm{v} / \mathrm{v}$ suspension made by isotonic phosphate buffer of $154 \mathrm{mM} \mathrm{NaCl}$ in $10 \mathrm{mM}$ Sodium Phosphate Buffer at $\mathrm{pH} 7.4$ used as Stock erythrocyte or RBC suspension.

Hypotonic solution-induced haemolysis: The activity of the synthesized compounds was performed according to the reported method. ${ }^{25}$ The test sample consisted of stock erythrocyte (RBC) suspension $0.5 \mathrm{~mL}$ mixed with $5 \mathrm{~mL}$ of hypotonic solution $(50$ $\mathrm{mM} \mathrm{NaCl}$ in $10 \mathrm{mM}$ Sodium Phosphate Buffered saline at $\mathrm{pH} 7.4$ ) containing different concentrations of sample $(20,40,60,80$ and 100 $\mu \mathrm{M} / \mathrm{mL}$ ). The control consists of $0.5 \mathrm{~mL} \mathrm{RBC}$ suspension mixed with 5 $\mathrm{mL}$ of hypotonic buffered solution alone. The mixtures were incubated for 10 minutes at room temperature, centrifuged for 10 minutes at 3000 $\mathrm{rpm}$ and supernatant was measured by spectrophotometrically at 540 $\mathrm{nm}$. The \% inhibition of haemolysis was calculated from the following formula.

$$
\% \text { Inhibition of haemolysis }=\left[\frac{\mathrm{A}_{1}-\mathrm{A}_{2}}{\mathrm{~A}_{1}}\right] \times 100
$$

Where:

$\mathrm{A}_{1}=$ Absorbance of hypotonic buffered solution alone.

$\mathrm{A}_{2}=$ Absorbance of test /standard sample in hypotonic solution.

\section{Conclusion}

In conclusion, we have synthesized a sequence of small and simple imidazole derived Schiff's base derivatives with various groups in benzene ring. All the synthesized analogues, compounds 9, 10, 11, 15, 16,22 and 23 with $\mathrm{OH}$ and $\mathrm{OCH}_{3}$ groups in benzene ring exhibited stronger radical scavenging activities than BHT and BHA in all the three assays performed. Compounds 5, 6, 7, 8, 12, 13, 14 and 21 with $\mathrm{Cl}, \mathrm{F}, \mathrm{NO}_{2}$ and $\mathrm{Br}$ in benzene ring demonstrated excellent antiinflammatory activity than aspirin and indomethacin.

\section{Acknowledgement}

All authors are thankful to Sri Ram Chem management for their continuous encouragement towards research.

\section{References}

1. Timmerman H (2007) Reflection of medicinal chemistry since the 1950s Compr Med Chem 8: 7-15.

2. Kashyap SJ, Sharma PK, Garg VK, Dudhe R, Kumar N (2011) Review on synthesis and various biological potential of thiazolopyrimidine derivatives. $J$ Adv Sci Res 2: 18-24.

3. Husain A, Drabu S, Kumar N, Alam MM, Bawa S (2013) Synthesis and biologica evaluation of di- and tri-substituted imidazoles as safer anti-inflammatoryantifungal agents. J Pharm Bioallied Sci 5: 154-161.

4. Sorrenti V, Salerno L, Giacomo C, Acquaviva R, Siracusa MA, et al. (2006) Imidazole derivatives as antioxidants and selective inhibitors of Nnos. Nitric Oxide 14: $45-50$

5. Vijesh AM, Isloor AM, Telkar S, Peethambar SK, Rai S, et al. (2011) Synthesis characterization and antimicrobial studies of some new pyrazole incorporated imidazole derivatives. Eur J Med Chem 46: 3531-3536.

6. Yang X, Wan W, Deng X, Li Y, Yang L, et al. (2012) Design, synthesis and cytotoxic activities of novel hybrid compounds between 2-phenylbenzofuran and imidazole. Bioorg Med Chem Lett 22: 2726-2729.

7. LuX, Liu X, Wan B, Franzblau SG, Chen L, et al. (2012) Synthesis and evaluation of anti-tubercular and antibacterial activities of new 4-(2,6-dichlorobenzyloxy) phenyl thiazole, oxazole and imidazole derivatives. Part 2. Eur J Med Chem 49: 164-171.

8. Zhan P, Liu X, Zhu J, Fang Z, Li Z, et al. (2009) Synthesis and biological evaluation of imidazole thioacetanilides as novel non-nucleoside HIV-1 reverse transcriptase inhibitors. Bioorg Med Chem 17: 5775-5781. 
Citation: Shantharam CS, Swaroopa M, Darshini N, Mallesha N, Rakesh KP (2017) Synthesis and SAR Studies of Potent Antioxidant and AntiInflammatory Activities of Imidazole Derived Schiff Base Analogues. Biochem Anal Biochem 6: 314. doi: 10.4172/2161-1009.1000314

9. Sorg O (2004) Oxidative stress: A theoretical model or a biological reality. Biol 327: 649-662.

10. Valko M, Rhodes CJ, Monocol J, Izakovic M, Mazur M (2006) Free radicals, metals and antioxidants in oxidative stress-induced cancer. Chem Biol Interact 160: $1-40$.

11. Halliwell B, Gutteridge JMC (1999) Free Radicals in Biology and Medicine, (3rd edn) Oxford University Press.

12. Bandgar BP, Adsul LK, Chavan HV, Jalde SS, Shringare SN, et al. (2012) Synthesis, biological evaluation, and docking studies of 3-(substituted)-aryl5-(9-methyl-3-carbazole)-1H-2-pyrazolines as potent anti-inflammatory and antioxidant agents. Bioorg Med Chem Lett 22: 5839-5844.

13. Nakayama T, Yamada M, Osawa T, Kawakishi S (1993) Suppression of active oxygen-induced cytotoxicity by flavonoids. Biochem Pharmacol 45: 265-267.

14. Palomer A, Cabre F, Pascual J, Campos J, Trugillo MA, et al. (2002) Identification of novel cyclooxygenase-2 selective inhibitors using pharmacophore models. J Med Chem 45: 1402-1411.

15. Gupta SPBN, Moorthy NSHN (2007) Synthesis and physicochemical characterization of mutual prodrug of indomethacin. Trends Appl Sci Res 2: 165-169.

16. Rakesh KP, Manukumar HM, Gowda DC (2015) Schiff's bases of quinazolinone derivatives: Synthesis and SAR studies of a novel series of potential antiinflammatory and antioxidants Bioorg Med Chem Lett 25: 1072-1077.

17. Rakesh KP, Shantharam CS, Manukumar HM (2016) Synthesis and SAR studies of potent $\mathrm{H}+/ \mathrm{K}+-A T P a s e$ inhibitors of quinazolinone-Schiff's base analogues. Bioorg Chem 68: 1-8.

18. Rakesh KP, Suhas R, Chandan S, Manukumar HM, Gowda DC (2015) Quinazolinones linked amino acids derivatives as a new class of promising antimicrobial, antioxidant and anti-inflammatory agents. Eur J Chem 6: 254-260.

19. Kaur J, Bhardwaj A, Huany Z, Knaus EE (2012) N-1 and C-3 substituted indole Schiff bases as selective COX-2 inhibitors: synthesis and biological evaluation. Bioorg Med Chem Lett 22: 2154-2159.

20. Correia C, Leite C, Proenca MF, Carvalha MA (2014) Synthesis and radical scavenging activity of phenol-imidazole conjugates. Bioorg Med Chem Lett 24: 2768-2772.

21. Narang R, Sharma S, Narasimhan B (2012) Evaluation of Anti-inflammatory activity of acid Hydrazide derivatives. Hygeia J Drug Med 4: 15-20.

22. Blois MS (1958) Antioxidant determinations by the use of a stable free radical Nature 181: 1199-1200.

23. Re R, Pellegrini N, Proteggente A, Pannala A, Yang M, et al. (1999) Antioxidant activity applying an improved ABTS radical cation decolorization assay. Radical Bio Med 26: 1231-1237.

24. Fogliano V, Verde V, Randazzo G, Ritieni A (1999) Method for measuring antioxidant activity and its application to monitoring the antioxidant capacity of wines. J Agric Food Chem 47: 1035-1040.

25. Shinde UA, Phadke AS, Nair AM, Mungantiwar AA, Dikshit VJ, et al. (1999) Membrane stabilizing activity: A possible mechanism of action for the antiinflammatory activity of Cedrus deodara wood oil. Fitoterapia 70: 251-257. 